\title{
Derechos de autor: la exposición de Barragán
}

\author{
Ángel Villalba Roldán e Iván Hernández Quintero
}

\section{Resumen}

En este video se explican los conceptos fundamentales sobre derecho de autor, derechos conexos y gestión colectiva de derechos de autor. Se presenta brevemente la aplicabilidad de estos en el caso de la exposición "ill Magid. Una carta siempre llega a su destino. Los Archivos Barragán" (2017). El contenido nos invita a reflexionar sobre la importancia de los derechos de autor y su relevancia en el contexto mexicano.

Palabras clave: derechos de autor; Jill Magid; Luis Barragán; México.

\section{COPYRIGHT: the EXHIBITION ABOUT BARRAGAN}

\begin{abstract}
This video explains the fundamental concepts of copyright, related rights and collective management of copyright. The applicability of these is briefly presented in the case of the exhibition "Jill Magid. Una carta siempre llega a su destino. Los Archivos Barragán" (2017). The content invites us to reflect on the importance of copyright and its relevance in the Mexican context.
\end{abstract}

Keywords: copyright; Jill Magid; Luis Barragan; Mexico. 


\section{Ángel Villalba Roldán}

villalbarmx@gmail.com

Lic. en Bibliotecología y Estudiante de la Maestría en Bibliotecología y Estudios de la Información, ambas por la UNAM. Catalogador de publicaciones seriadas, con el nombramiento de Técnico Académico en el Instituto de Investigaciones Bibliográficas-Hemeroteca Nacional de México. Realizó dos intercambios como profesor invitado en Texas A\&M University, en el proyecto "Discovering a New World" y actualización en la Catalogación de Publicaciones Seriadas.

\section{Iván Hernández Quintero}

ivanhq94@gmail.com

Pasante de Ingeniería en Telecomunicaciones, por la Facultad de Ingeniería de la UNAM; estudiante de Derecho en la Universidad Latina; Director General de Taxho Engineering, presidente del consejo de socios de Influencers Maker, socio Rotaract y amante de las causas sociales.

Video. Clic para ver el video.

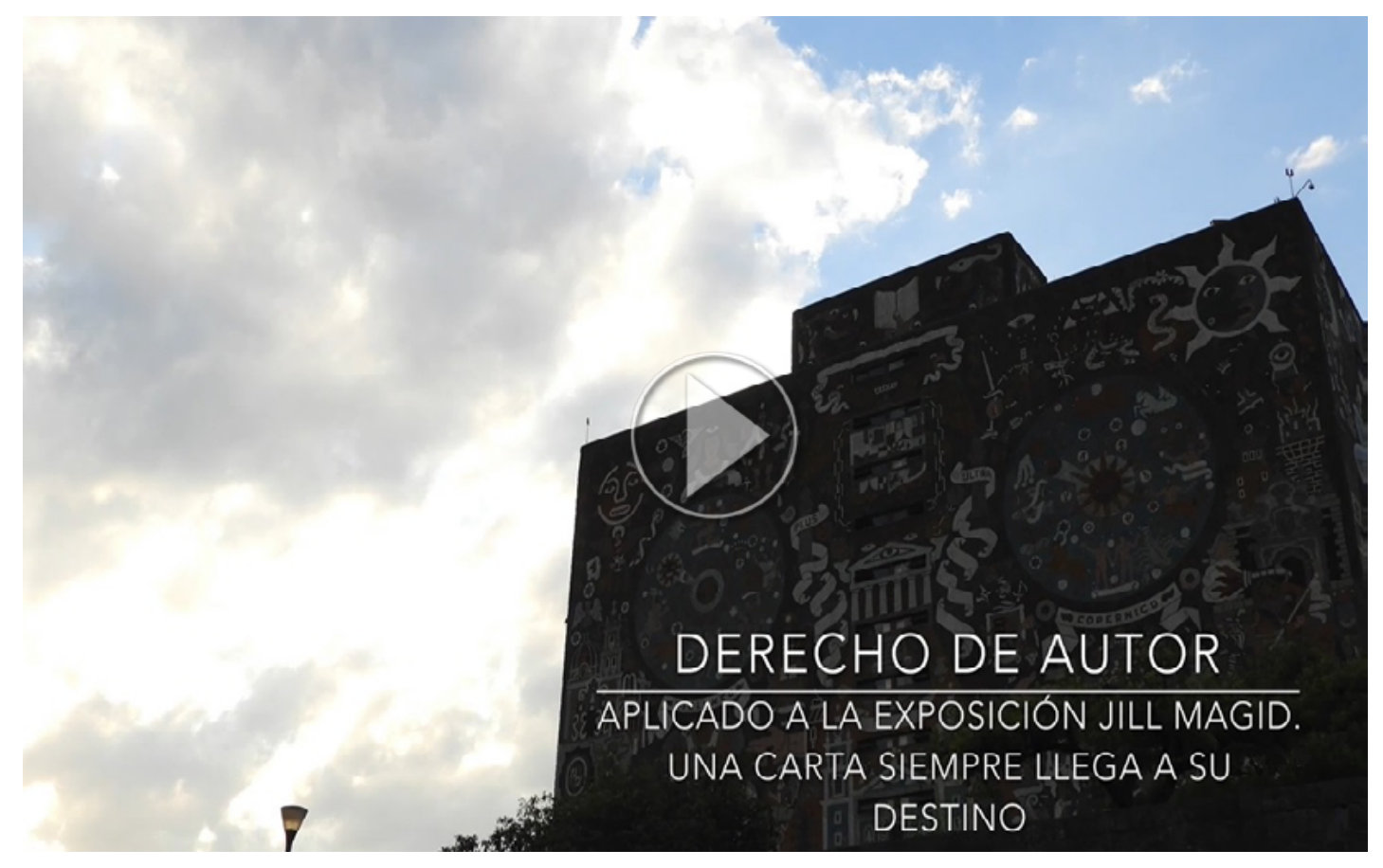

\section{Cómo citar este artículo}

* Villalba Roldán, A. y Hernández Quintero, I. (2019). Derechos de autor: la exposición sobre Barragan. Revista Digital Universitaria (RDU). Vol. 20, núm. 2 marzo-abril. DoI: http://doi.org/10.22201/codeic.16076079e.2019.v20n2.a10 